\title{
Low dose intraoperative ketamine infusion with multilevel paravertebral block for pain after video-assisted thoracic surgery: a randomized-controlled study
}

\author{
Sirilak Suksompong ${ }^{1 \wedge}$, Nophanan Chaikittisilpa ${ }^{1} \wedge$, Suthatip Wanchiange ${ }^{1}$, Suppachai Poolsuppasit $^{1}$, \\ Punnarerk Thongcharoen $^{2} \wedge$, Panop Limratana ${ }^{1 \wedge}$ \\ ${ }^{1}$ Department of Anesthesiology, Faculty of Medicine, Siriraj Hospital, Mahidol University, Bangkok, Thailand; ${ }^{2}$ Division of Cardiothoracic Surgery, \\ Department of Surgery, Faculty of Medicine, Siriraj Hospital, Mahidol University, Bangkok, Thailand \\ Contributions: (I) Conception and design: S Suksompong, N Chaikittisilpa, P Thongcharoen, P Limratana; (II) Administrative support: S Wanchiange, \\ P Limratana; (III) Provision of study materials or patients: S Suksompong, S Poolsuppasit, P Thongcharoen, P Limratana; (IV) Collection and \\ assembly of data: S Suksompong, S Wanchiange, P Limratana; (V) Data analysis and interpretation: S Suksompong, N Chaikittisilpa, P Limratana; (VI) \\ Manuscript writing: All authors; (VII) Final approval of manuscript: All authors. \\ Correspondence to: Nophanan Chaikittisilpa, MD. Department of Anesthesiology, Faculty of Medicine, Siriraj Hospital, Mahidol University, Wang \\ Lang Road, Siriraj, Bangkoknoi district, Bangkok, 10700, Thailand. Email: nophanan.chi@mahidol.edu.
}

Background Intraoperative low-dose ketamine infusion has been reported to be an effective adjuvant to opioids for postoperative pain control without major side effects, but it has not been tested in videoassisted thoracic surgery (VATS). The aim of this study was to examine the effect of low-dose intraoperative intravenous ketamine infusion on 24-hour morphine requirement and acute postoperative pain following VATS for lung resection.

Methods: This study was a single center, randomized, double-blind, placebo-controlled study. Thirtytwo patients undergoing elective VATS for lung resection in a university hospital were included. Patients were randomly allocated (1:1 ratio) to receive either intraoperative low-dose ketamine $(0.2 \mathrm{mg} / \mathrm{kg} / \mathrm{h})$ or normal saline infusion starting from intubation to the beginning of chest closure. All patients received multilevel thoracic paravertebral block (TPVB) and morphine was administered postoperatively via the patient-controlled analgesia pump using the same protocol. Time to first analgesia, postoperative cumulative morphine doses at 10, 30 minutes, and the consecutive 1, 2, 6, 12, 18, and 24 hours were recorded. Pain intensity during rest and deep breathing were also assessed by numeric rating scale (NRS) score at 1- and 24-hour postoperatively.

Results: There was no significant difference in median $\left(\mathrm{P}_{25}, \mathrm{P}_{75}\right)$ cumulative 24-hour morphine requirement between the ketamine and the control groups $[15(5.5,29.5)$ vs. $22.5(15.3,40.8) \mathrm{mg}, \mathrm{P}=0.090]$. Patients in ketamine group had significantly longer median pain free time than the control group (27 vs. 2 minutes, $\mathrm{P}=0.006$ ). No difference in overall NRS score at rest or during deep breathing at 1- and 24-hour postoperatively was demonstrated $(\mathrm{P}=0.861)$.

Conclusions: Intraoperative low dose ketamine infusion in addition to TPVB does not reduce postoperative morphine consumption or pain intensity but may prolong pain free time in patients undergoing VATS for lung resection.

Keywords: Video-assisted thoracic surgery (VATS); perioperative; acute pain; ketamine; N-methyl-D-aspartate (NMDA) antagonists

\footnotetext{
^ ORCID: Sirilak Suksompong, 0000-0002-4288-1331; Nophanan Chaikittisilpa, 0000-0002-4210-8066; Suppachai Poolsuppasit, 0000-0001-92577605; Punnarerk Thongcharoen, 0000-0002-0420-1462; Panop Limratana, 0000-0002-7703-8256.
} 
Submitted Apr 01, 2021. Accepted for publication May 27, 2021.

doi: 10.21037/apm-21-766

View this article at: https://dx.doi.org/10.21037/apm-21-766

\section{Introduction}

Video-assisted thoracic surgery (VATS) is a minimally invasive technique for lung resection which has been shown to reduce postoperative pain and promotes a faster recovery when compared to conventional (open) thoracotomy $(1,2)$. Adequate pain control following thoracic surgery allows early ambulation and recovery, and reduces postoperative pulmonary complications $(3,4)$. Multimodal analgesic techniques, including non-steroidal anti-inflammatory drugs, paracetamol, local infiltration and regional block, have been used over the years in attempt to lessen postoperative pain, as well as minimize opioid consumption and opioid-related side effects $(5,6)$. Still, significant postthoracotomy pain was reported in 27 to 63 percent after $\operatorname{VATS}(7,8)$.

Ketamine, a non-competitive $\mathrm{N}$-methyl-D-aspartate (NMDA) receptor antagonist, was originally introduced as an anesthetic drug. Ketamine has gained growing interests for its analgesic actions at subanesthetic dose and has been extensively studied for its effect on postoperative pain $(9,10)$. However, the results are inconsistent due to the variations in dosing, duration and route of ketamine administration among studies $(9,11)$.

For acute post-thoracotomy pain, results from previous randomized-controlled studies also favored the benefit of perioperative low-dose ketamine in lower pain scores and opioid consumption (12). Most of the studies were performed in open thoracotomy procedures, while published studies of ketamine in VATS are few. Moreover, in spite of heterogeneity in the regimens of administration, ketamine infusion was usually continued during 24-72 hours postoperatively in most studies $(9,12)$. Despite the popularity of postoperative ketamine infusion in the literature, the concerns over the known psychomimetic side effects have limited its generalizability (13). Intraoperative low-dose ketamine infusion has also been reported to be an effective adjuvant to opioids for postoperative pain control without major side effects (14-19), but it has not been tested in VATS. Given that VATS is less invasive than open thoracotomy (2), we hypothesized that intraoperative ketamine might be an adequate adjunct to multilevel thoracic paravertebral block (TPVB) to reduce postoperative pain and opioid consumption after VATS.

The aim of this study was to examine the effect of low-dose intraoperative intravenous ketamine infusion $(0.2 \mathrm{mg} / \mathrm{kg} / \mathrm{h})$, when combined with multilevel TPVB, on 24-hour morphine requirement and acute postoperative pain following VATS for lung resection. We present the following article in accordance with the CONSORT reporting checklist (available at https://dx.doi.org/10.21037/ apm-21-766).

\section{Methods}

This study was a single center, randomized, doubleblind, placebo-controlled study, conducted at Siriraj Hospital, a 2,200-bed quaternary-care medical center located in Bangkok, Thailand. The study was conducted in accordance with the Declaration of Helsinki (as revised in 2013). The study protocol was approved by the Siriraj Institutional Review Board (Si 513/2017) and was registered at clinicaltrials.gov (NCT03280017). Patients scheduled for elective VATS for lung resection aged 18-70 years old and capable of using patient-controlled analgesia (PCA) device were included. Exclusion criteria were known hypersensitivity to morphine, ketamine or levobupivacaine, contraindications to or failed TPVBs, body mass index (BMI) $>35 \mathrm{~kg} / \mathrm{m}^{2}$, and the likelihood of postoperative mechanical ventilation.

\section{Study groups and intervention}

Between October 2017 and December 2018, all patients scheduled for elective VATS were screened for eligibility criteria and enrolled to the study (PL, SW). After informed consents were obtained, participants were randomly allocated (1:1 ratio) to receive either intraoperative low-dose ketamine or normal saline infusion. Randomization was done using computer-generated method by a statistician. Blocks of 4 were used. Randomization sequence was kept separately in opaque sealed envelopes with running numbers (1 to 32$)$.

During the preoperative visits, participants were instructed 
about postoperative pain assessment with numeric rating scale (NRS) score and the use of the PCA device. Premedication with analgesics or sedatives were not given before arrival to the operating theater. After placement of standard ASA monitoring, all participants were given $0.2-0.5 \mathrm{mcg} / \mathrm{kg}$ of dexmedetomidine infusion in 10 minutes and $0.5 \mathrm{mcg} / \mathrm{kg}$ of fentanyl intravenously and then were placed in prone position. Ultrasound-guided multilevel TPVB was performed at the T4 and T5 levels on the side of the operation. The ultrasound transducer was placed in the transverse plane lateral to the designated spinous process. The transverse process, posterior intercostal space, pleura, and paravertebral space were identified. A 4-inch SonoTap (PAJUNK ${ }^{\circledR}$, Germany) needle was inserted using in-plane technique from lateral to medial plane. Once paravertebral space was reached, $2 \mathrm{~mL}$ of normal saline was injected to demonstrate anterior displacement of the pleura. Then, $10 \mathrm{~mL}$ of $0.5 \%$ levobupivacaine (Abbvie ${ }^{\circledR}, \mathrm{UK}$ ) was injected into each paravertebral space (total of $20 \mathrm{~mL}$ ) under ultrasound visualization. All TPVBs were performed by one of the three authors (SS, PL, SP). All participants were assessed for upper and lower levels of blockade using cold swabs at 10 minutes after the TPVBs. Anesthesia was then induced with $1-2 \mathrm{mg} / \mathrm{kg}$ propofol, $1 \mathrm{mcg} / \mathrm{kg}$ fentanyl and $0.2 \mathrm{mg} / \mathrm{kg}$ cisatracurium and maintained with sevoflurane in air/oxygen mixture. Double lumen endobronchial tube was used to establish one-lung ventilation.

After the analgesic levels were confirmed, the envelopes containing the group allocation number were opened, and the study drug was prepared by the anesthesia personnel not involving in the study or patient care. Racemic ketamine (Hameln, Germany) was prepared in normal saline to $50 \mathrm{mg}$ in $50-\mathrm{mL}$ syringe $(1 \mathrm{mg} / \mathrm{mL})$ for patients in the ketamine group. Normal saline was also prepared in the $50-\mathrm{mL}$ syringe identical to ketamine for patients in the control group. Each syringe was labelled as 'study drug'. Participants received study drugs according to their group allocation. Study drug was infused at the rate of $0.2 \mathrm{~mL} / \mathrm{kg} / \mathrm{h}$ starting immediately after double-lumen endobronchial tube was placed and continued throughout the intraoperative period. The study drug infusion was discontinued at the beginning of chest closure. The participants, as well as, the anesthesiologists involving in providing paravertebral blocks and intraoperative cares were blinded to group allocation.

During the intraoperative period, fentanyl $0.5-1 \mathrm{mcg} / \mathrm{kg}$ boluses were given if the systolic blood pressure was elevated more than $20 \%$ from baseline. End-tidal sevoflurane concentration was maintained at $0.8-1$ ageadjusted minimal alveolar concentration. Hypotension was defined as a $20 \%$ reduction in systolic blood pressure from baseline and was treated with a bolus of $6 \mathrm{mg}$ of ephedrine and/or $4 \mathrm{mcg}$ of norepinephrine. All participants were extubated at the end of surgery and transferred to the post anesthesia care unit (PACU). Intravenous PCA device (Sapphire ${ }^{\mathrm{TM}}$, ICU Medical, Inc., US) was provided from PACU arrival until the $24^{\text {th }}$ hour after surgery. Morphine was administered via the PCA pump using the same protocol for all patients (bolus $1 \mathrm{mg}$, lockout interval 5 minutes, 4-hour limit $30 \mathrm{mg}$ ).

\section{Outcomes}

The primary outcome of the study was 24-hour cumulative morphine dosage. Time from the end of the surgery to the time of first PCA device triggering was obtained from PCA device logs. Postoperative cumulative morphine doses at 10,30 minutes, and the consecutive $1,2,6,12,18$, and 24 hours were also recorded.

Pain intensity during rest and deep breathing were assessed using NRS score $0-10(0=$ no pain, $10=$ worse pain) at 1 - hour and 24-hour postoperatively. The peak expiratory flow rates (PFR) were measured using a portable peak flow meter (MicroPeak ${ }^{\circledR}$, CareFusion, USA) during the preoperative visits, and at 24-hour after surgery. The percentage difference between preoperative and postoperative PFR was calculated as [(preoperative PFR postoperative $\mathrm{PFR}) /$ preoperative $\mathrm{PFR}] \times 100$. Occurrence of nausea and vomiting (PONV), hallucinations, nightmares, delirium and requirement for antiemetic therapy were also recorded. All outcome accessors were also blinded to group allocation.

\section{Statistical analysis}

Sample size was calculated based on a previous study by Kaya et al. (20), which demonstrated a 24-hour cumulative morphine consumption of $32 \pm 5 \mathrm{mg}($ mean $\pm \mathrm{SD})$ after VATS in patients receiving multilevel TPVB using $20 \mathrm{~mL}$ of $0.5 \%$ bupivacaine. A $20 \%$ reduction in the 24-hour cumulative morphine consumption anticipated in the ketamine group compared with the normal saline group (control) was hypothesized. Using 2-sided type I error of 0.05 and $90 \%$ power, a sample of 16 participants per group was required. Query Advisor 3.0 (Statistical Solutions Ltd, Cork, Ireland) was used for sample size estimation. Data 


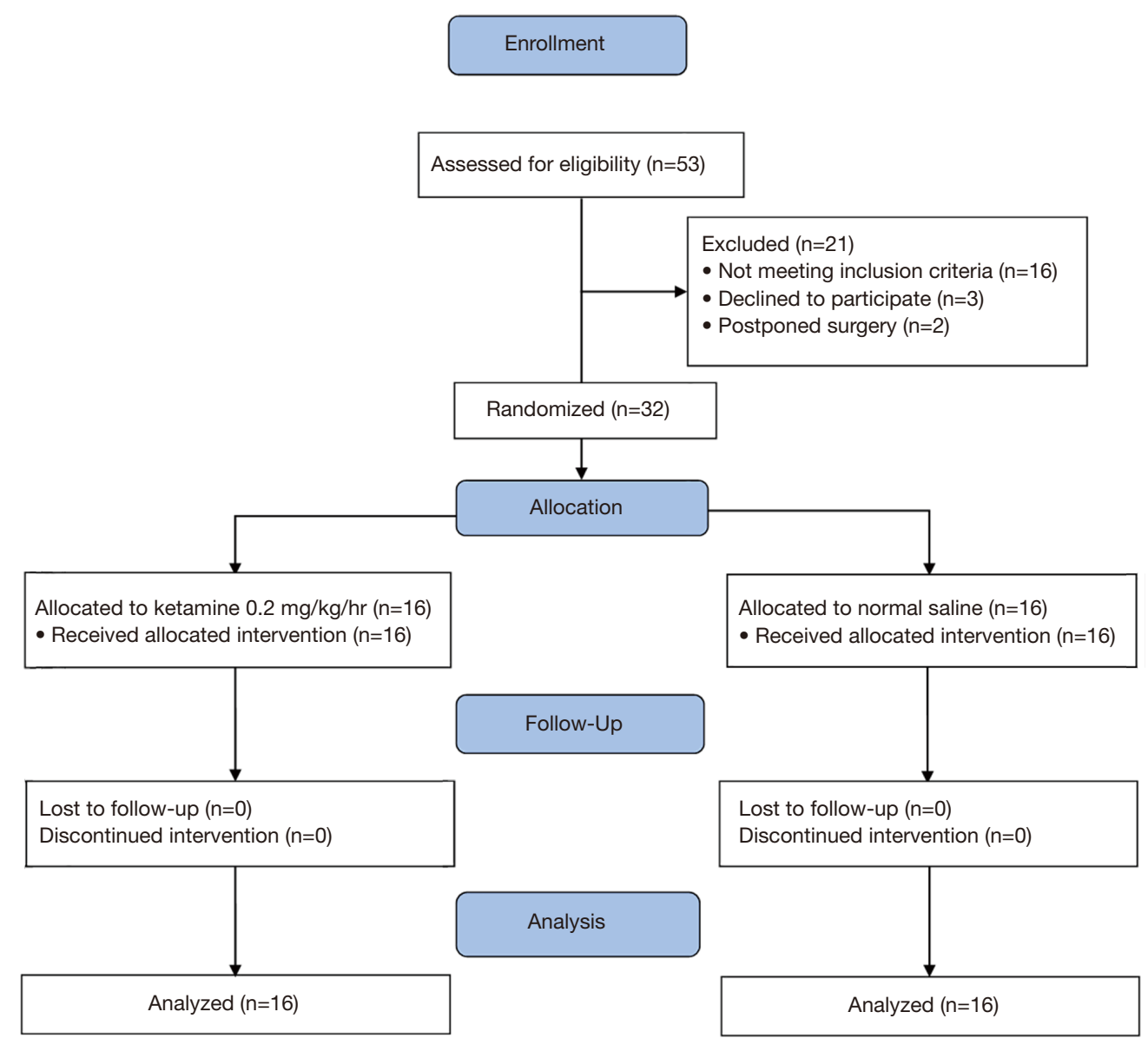

Figure 1 CONSORT flow diagram.

were processed using SPSS Statistics for Windows version 18 (SPSS Inc., Chicago, Ill, USA). Continuous data such as age, BMI, duration of surgery, duration of anesthesia, drug doses, percentage difference between preoperative and postoperative PFR, NRS score and 24-hour morphine consumption are presented as mean $\pm \mathrm{SD}$ or median $\left(\mathrm{P}_{25}\right.$, $\mathrm{P}_{75}$ ). Demographic and perioperative data were compared using Student's $t$-test or Mann-Whitney U test. NRS score and 24-hour morphine consumption were compared using Repeated Measurement ANOVA. Time to first PCA-triggering was analyzed using survival analysis and generalized Wilcoxon's test for comparison of 2 survival curves. Categorical data such as gender and incidence of side effects are presented as number (\%) and compared using $\chi^{2}$ test. A $\mathrm{P}$ value less than 0.05 was considered statistically significant.

\section{Results}

From October 2017 to December 2018, 32 participants were enrolled (16 participants in each group) and completed the study (Figure 1). Mean age was $55.8 \pm 10.8$ years and $68.8 \%$ were female. There were no significant differences in patient demographic data between the two groups (Table 1). Despite randomization, $13(81.3 \%)$ patients in the control group underwent lobectomy/segmentectomy, and only $6(37.5 \%)$ patients in the ketamine group had the same procedure $(\mathrm{P}=0.012)$. Moreover, the duration of surgery was significantly longer in the control group compared to the ketamine group (153.6 \pm 67.0 vs. $95.3 \pm 51.0$ minutes, $\mathrm{P}=0.009)$. The total intraoperative ketamine dose administered was $0.34 \pm 0.15 \mathrm{mg} / \mathrm{kg}$ in the ketamine group. There were no differences in intraoperative dexmedetomidine and fentanyl doses (Table 2). Successful TPVB was achieved in 
Table 1 Baseline patient characteristics

\begin{tabular}{lcc}
\hline Variables & Ketamine $(\mathrm{n}=16)$ & Normal saline $(\mathrm{n}=16)$ \\
\hline Age (years) & $53.5 \pm 11.9$ & $58.0 \pm 9.4$ \\
Weight $(\mathrm{kg})$ & $62.3 \pm 12.6$ & $63.2 \pm 12.8$ \\
Height $(\mathrm{cm})$ & $161.5 \pm 8.1$ & $157.5 \pm 6.9$ \\
BMl $\left(\mathrm{kg} / \mathrm{m}^{2}\right)$ & $23.8 \pm 4.3$ & $25.4 \pm 4.1$ \\
Female & $10(62.5)$ & $12(75.0)$ \\
\hline
\end{tabular}

Values are presented as mean \pm standard deviation or number of patients (\%). BMI, body mass index.

Table 2 Perioperative characteristics

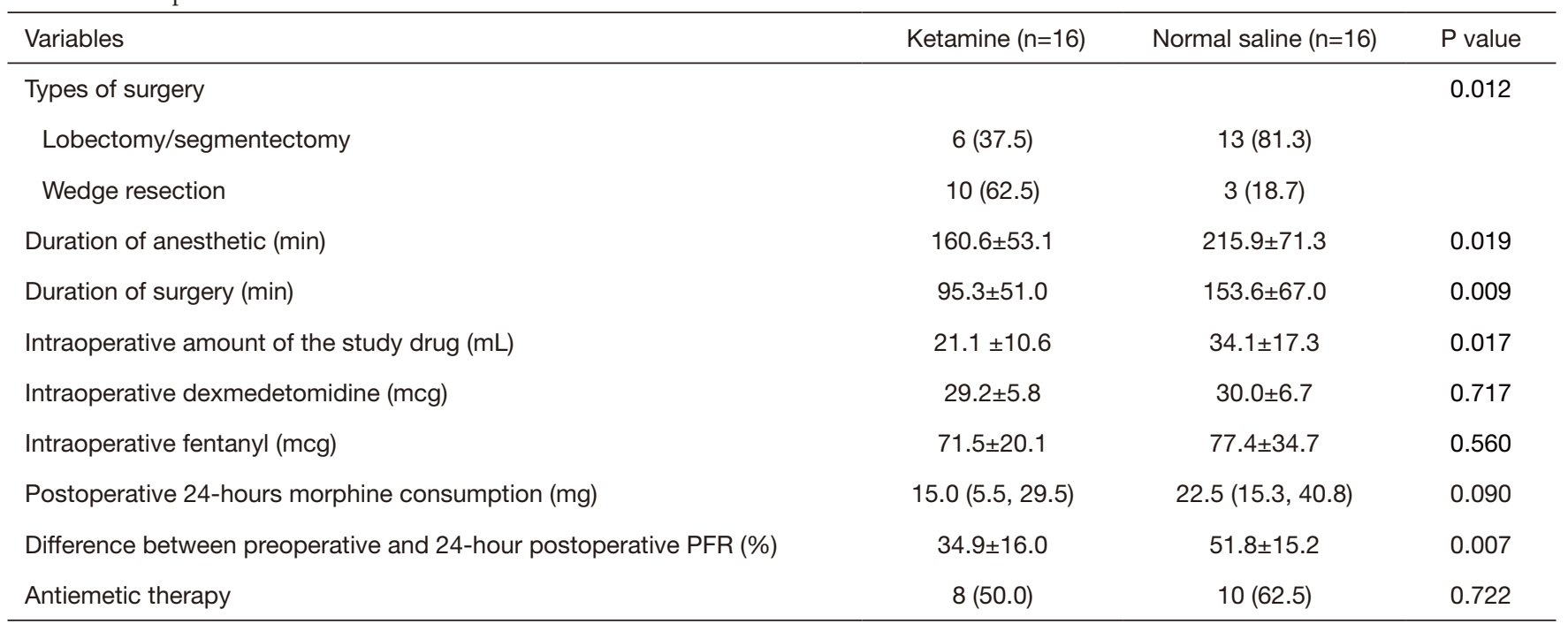

Values are presented as mean \pm standard deviation, median $\left(\mathrm{P}_{25}, \mathrm{P}_{75}\right)$ or number of patients $(\%)$. Difference between preoperative and $24-$ hour postoperative peak flow rate $(\mathrm{PFR})=[($ preoperative PFR - postoperative PFR)/preoperative PFR $] \times 100(\%)$.

all patients. Analgesic levels after paravertebral blocks were shown in Figure 2.

There was no significant difference in the median $\left(\mathrm{P}_{25}\right.$, $\mathrm{P}_{75}$ ) cumulative 24-hour morphine consumption between the ketamine $[15(5.5,29.5) \mathrm{mg}$ and the control group 22.5 (15.3, 40.8) mg, $\mathrm{P}=0.090$ ] (Figure 3), however, longer median pain free time was observed in the ketamine group at 27 minutes compared to 2 minutes in the control group $(\mathrm{P}=0.006)$ (Figure 4). No difference in postoperative NRS score at 1- and 24-hour at rest and during deep breathing was observed $(\mathrm{P}=0.861)$ (Figure 5). The control group had higher percentage difference between preoperative and postoperative PFR than the ketamine group $(51.8 \% \pm 15.2 \%$ vs. $34.9 \% \pm 16.0 \%, \mathrm{P}=0.007)$. There was no difference in antiemetic use and none of the participants reported postoperative nightmares, hallucinations or delirium.

\section{Discussion}

The main finding from this study is that, in patients undergoing VATS for lung resection with single shot multilevel TPVB, intraoperative low dose ketamine infusion does not reduce 24-hour morphine consumption, and postoperative NRS score at rest and movement compared to placebo, however, it prolongs the time to first analgesic requirement.

Several studies have investigated the efficacy of intravenous ketamine on acute postoperative thoracotomy pain (12,19,21-25). There is no consensus in standard dose, timing and route of administration of ketamine among studies (12). A systematic review of perioperative ketamine used for thoracotomy pain by Moyse et al., which included 15 randomized control trials, reported a significant reduction in acute postoperative pain. 

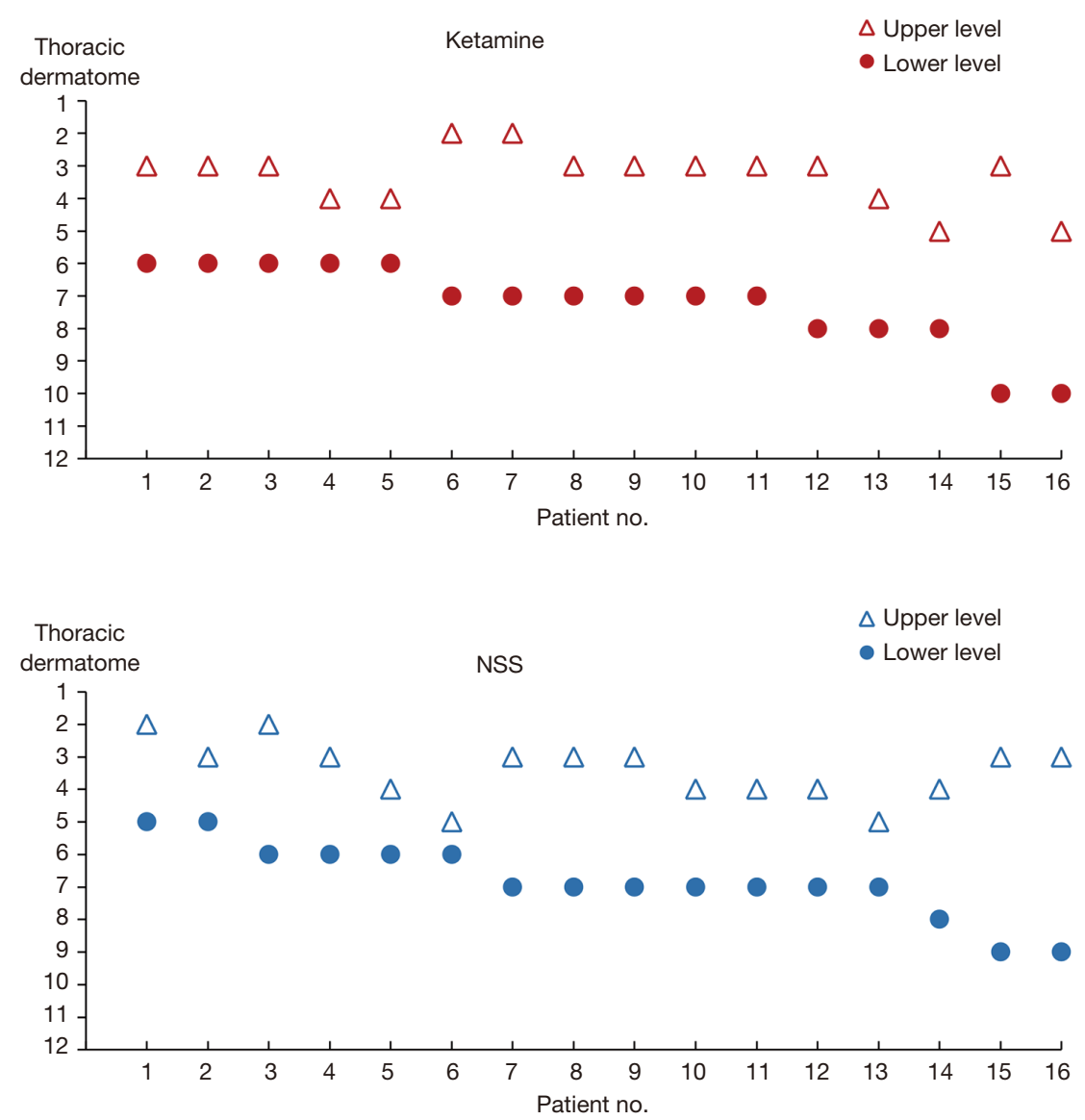

Figure 2 Spreading of levels of sensory blockade in ketamine group (upper panel) and normal saline group (lower panel) at 10 minutes after single shot multilevel thoracic paravertebral block.

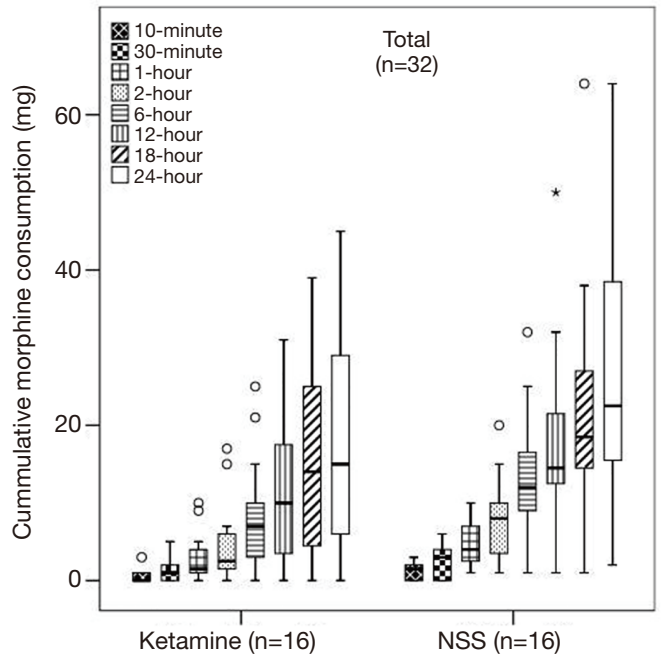

Figure 3 Median boxplot $\left(\mathrm{P}_{25}, \mathrm{P}_{75}\right)$ with bars showing the cumulative morphine consumption during the first 24 hours postoperatively $(\mathrm{P}=0.090)$.

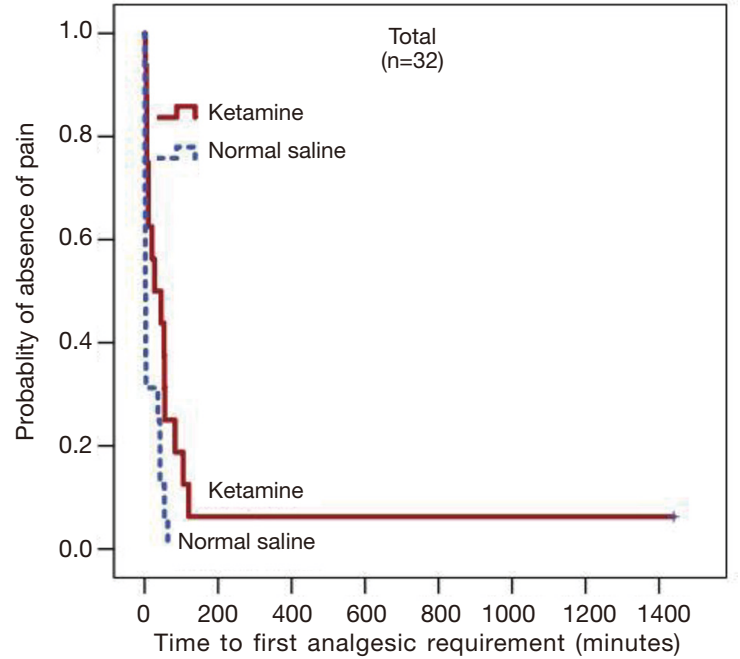

Figure 4 Kaplan-Meier survival curve of time to first trigger of patient-controlled analgesia (PCA) machine in the ketamine and the control groups $(\mathrm{P}=0.006)$. 


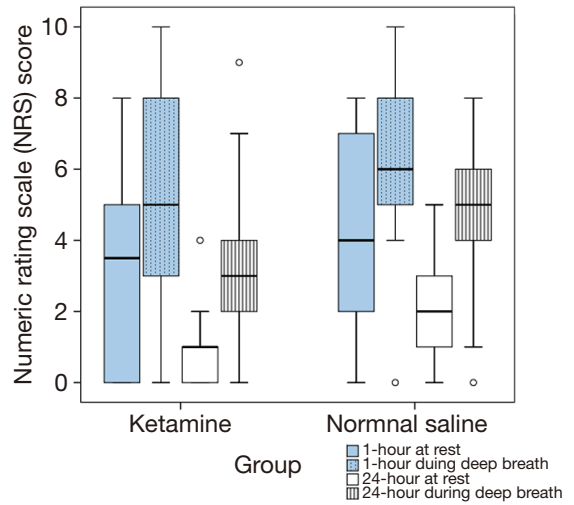

Figure 5 Median boxplot $\left(\mathrm{P}_{25}, \mathrm{P}_{75}\right)$ with bars showing the median and the $10^{\text {th }}$ and $90^{\text {th }}$ percentiles and open circles showing the extremes of numeric rating scale (NRS) score at 1- and 24-hour postoperative at rest and during deep breath $(\mathrm{P}=0.861)$.

Among the 15 studies, ketamine was given intravenously via infusion or IV PCA in 11 studies and positive results were demonstrated in 7 studies (470 participants) (12). Although different regimens were used, in all positive studies, ketamine was continued to $48-72$ hours postoperatively $(19,23,26-30)$. The authors concluded that ketamine was effective in attenuating acute post-thoracotomy pain (12). To our knowledge, our study is among the first studies to examine analgesic effects of intraoperative low-dose ketamine in VATS for lung resection.

Intraoperative bolus and/or infusion of low-dose ketamine was assessed in several studies $(9,11)$. Despite some inconsistency, an opioid-sparing effect of intraoperative low-dose ketamine has been demonstrated after abdominal $(15,18,31)$, orthopedics (32-34) and gynecologic procedures (35). However, for thoracotomy procedures, only one study (40 patients) had compared preincisional ketamine bolus $(0.5 \mathrm{mg} / \mathrm{kg})$ and placebo which the authors reported no difference in pain scores or opioid consumption (24). Due to concerns related to the dose-related side effects of ketamine, such as dysphoria and hallucination, we used low-dose intraoperative ketamine infusion which was discontinued at the end of the procedure. At sub-anesthetic dose $(<0.3 \mathrm{mg} / \mathrm{kg})$, the psychomimetic risk is believed to be insignificant (36,37). Moreover, intraoperative infusion is relatively simple and require less nursing care postoperatively at wards. Since the dose and mode of delivery varied greatly among the literatures, we have chosen the practical dose suggested by Gorlin et al., (0.1-0.3 mg/kg followed by $0.1-0.2 \mathrm{mg} / \mathrm{kg} /$ hour infusion) (36). Recent studies have demonstrated that single bolus dose of ketamine may be inefficient for postoperative pain $(38,39)$ and continuous intraoperative infusion was recommended (40). We also determined to specifically evaluate whether the intraoperative 'infusion only' regimen would yield the same effect when subanesthetic ketamine was combined with multilevel TPVB. Our hypothesis was that VATS resulted in less pain and tissue injury compared to open thoracotomy, therefore, we aimed to examine the effect of low-dose intraoperative ketamine rather than postoperative ketamine infusion. As a result, intraoperative infusion of $0.2 \mathrm{mg} / \mathrm{kg} /$ hour of ketamine was adopted.

In our study, we could not demonstrate the difference in 24-hour morphine consumption and postoperative pain between the intraoperative low-dose ketamine and the control groups. The negative results may be explained by several reasons. First, it is possible that the dose of intraoperative ketamine was inadequate. The dose of intraoperative ketamine used in our study was only $0.2 \mathrm{mg} / \mathrm{kg} /$ hour, which was relatively low to avoid possible side effects. In a dose-finding study by Suzuki et al. (23), the minimal effective plasma concentration that reduced postoperative pain was $20 \mathrm{ng} / \mathrm{mL}$ when ketamine was administered via thoracic epidurals. The reported doses of intravenous infusion of ketamine in previous studies, which demonstrated analgesic benefit, varied between $0.05-0.5 \mathrm{mg} /$ hour $(9,10)$. Most studies also started with a bolus dose of $0.15-0.5 \mathrm{mg} / \mathrm{kg}(9,10)$, in which, absence in our study. The mean duration of the surgery for the ketamine group in our study was only $95.3 \pm 51.0$ min resulting in small cumulative doses of ketamine, while the duration of surgery ranged between 2-4.6 hours in the other studies with positive results (15-17). Although ketamine is believed to have central desensitization effect after low dose administration due to its high affinity to NMDA receptors $(36,41)$, the mean cumulative dose of ketamine given for each patient in our study was only $21.1 \pm 10.6 \mathrm{mg}$ and may not reach effective plasma concentration $(20-150 \mathrm{ng} / \mathrm{mL})(40)$. Given that ketamine bolus was not utilized in our study, it is possible that sufficient plasma concentration was not achieved, especially, when the duration of surgery was short.

Secondly, TPVB may have already reduced 24-hour opioid requirement; hence, ketamine may not have provided additional analgesic benefit. Results from previous studies have confirmed the effectiveness of TPVB in acute post-thoracotomy pain control $(42,43)$. Borys et al. compared between TPVB and preemptive bolus ketamine 
in patients undergoing posterolateral thoracotomies and reported that TPVB was superior to ketamine in reducing pain intensity and morphine consumption (44). Ketamine has only moderate effect on acute postoperative pain $(36,40)$, therefore, its advantage is less likely to be shown when combined with other multimodal analgesia techniques $(25,45,46)$. In a study by Joseph $e t$ al., no difference in pain was reported in patients after open thoracotomy when higher dose of ketamine infusion for 48 hours was used in combination with thoracic epidural compared with placebo (22). Another study in thoracotomy patients by Yazigi et al. also could not demonstrate the difference in pain between ketamine infusion and placebo when multimodal analgesic techniques (intercostal nerve block, paracetamol and ibuprofen) were used in both groups (25). Moreover, all patients in our study were sedated with dexmedetomidine during TPVB. Dexmedetomidine is an alpha-2 adrenergic receptor agonist, which provides dose-dependent analgesia (47). Dexmedetomidine has been demonstrated as an effective adjuvant to opioids for postoperative pain after thoracic surgery (47-49). Although the doses administered in our study was low, intraoperative dexmedetomidine may have also decreased the postoperative pain, especially upon arrival at the PACU (50). Since VATS is associated with lower postoperative pain compared to traditional open thoracotomy $(2,51)$, when pain is partially suppressed with TPVB and dexmedetomidine, the benefit of adjunct ketamine may be subtle.

Furthermore, there were two categories of surgical procedures included in the present study; (I) lobectomy and segmentectomy, and (II) wedge resection. Most participants who underwent lobectomy were unintentionally randomized into the control group, whereas, most participants who underwent wedge resection were in ketamine group. Because VATS lobectomy is associated with longer duration and more extensive surgical approach compared to VATS wedge resection (52), subsequently, more intense postoperative pain is often observed (53). This may result in uneven postoperative pain intensity between the two groups, thus, a confounder in our study.

In our study, the patients in ketamine group had significantly less percent reduction of the 24-hour postoperative PFR from baseline compared to the control group. During early postoperative period, substantial impairment in the pulmonary function is frequently observed as a result of reduced lung volume, decreased lung compliance, respiratory muscles and diaphragmatic dysfunction after lung resection $(54,55)$. Low dose ketamine may have a protective effect on postoperative pulmonary function by stimulating respiration and offset opioidinduced respiratory depression (56-58). As an NMDA receptor antagonist, ketamine can attenuate central sensitization and results in lower opioid requirement in order to achieve the same analgesia, thus, reducing the undesirable side effects (59). Ketamine also has bronchodilator effect and its sympathomimetic activity is known to relieve airways spasm (60). Michelet et al. demonstrated better postoperative pulmonary function after lobectomy in patients receiving ketamine with morphine (1:1) via PCA when compared to PCA morphine alone on the first postoperative day (61). In their study, significant lower morphine consumption was demonstrated only after $36^{\text {th }}$ hour following surgery and no difference in pain scores were reported during the first day. However, in our study, the benefit of ketamine on the postoperative PFR changes may have been confounded by the disproportion of the procedure types (lobectomy versus wedge resection). The higher proportion of patients underwent wedge resection in the ketamine group can result in less complicated surgery, shorter duration of anesthesia, and a more substantial lung volume preserved. Furthermore, ketamine infusion was not extended through the postoperative period and neither reduction in pain nor opioid requirement could be demonstrated. Further studies using larger sample size with lobectomy procedures and continuous postoperative infusion for longer period are required to conclude the effects of ketamine on postoperative pain and pulmonary function.

There are limitations to this study. First, although our study was an RCT, discrepancies in perioperative characteristics were observed, which could be regarded as potential confounders. In our institution, VATS has mostly replaced conventional thoracotomy in the treatment of most lung pathologies, which results in the variety of procedural complexity and patient characteristics. Second, the small sample size had led to limitation for subgroup analysis to eliminate the confounders. Third, we did not give a bolus dose of ketamine before starting the infusion, therefore, the effective plasma concentration may have not reached in the shorter procedures. Finally, the use of nonsteroidal anti-inflammatory drugs, COX-inhibitors and paracetamol was omitted during the study period with the intention to emphasize the effects of ketamine, hence, this may not resemble routine practice.

In conclusion, intraoperative low dose ketamine infusion in addition to TPVB does not reduce postoperative 
morphine consumption or pain intensity but may prolong the pain free time in patients undergoing VATS for lung resection. The reduction in morphine consumption might be more pronounced using higher dose of ketamine or in more invasive VATS procedures.

\section{Acknowledgments}

We would like to thank Chulaluk Komoltri for her help in statistical analysis, Fontip Saetang for her assistance in the graphics and Nichapat Sooksri for her support in organizing this study.

Funding: This research project was supported by Siriraj Foundation Funding, Faculty of Medicine Siriraj Hospital, Mahidol University (Grant Number D003903).

\section{Footnote}

Reporting Checklist: The authors have completed the CONSORT reporting checklist. Available at https://dx.doi. org/10.21037/apm-21-766

Data Sharing Statement: Available at https://dx.doi. org/10.21037/apm-21-766

Peer Review File: Available at https://dx.doi.org/10.21037/ apm-21-766

Conflicts of Interest: All authors have completed the ICMJE uniform disclosure form (available at https://dx.doi. org/10.21037/apm-21-766). The authors have no conflicts of interest to declare.

Ethical Statement: The authors are accountable for all aspects of the work in ensuring that questions related to the accuracy or integrity of any part of the work are appropriately investigated and resolved. The study was conducted in accordance with the Declaration of Helsinki (as revised in 2013). The study protocol was approved by the Siriraj Institutional Review Board (Si 513/2017). Written informed consent was obtained from all participants.

Open Access Statement: This is an Open Access article distributed in accordance with the Creative Commons Attribution-NonCommercial-NoDerivs 4.0 International License (CC BY-NC-ND 4.0), which permits the noncommercial replication and distribution of the article with the strict proviso that no changes or edits are made and the original work is properly cited (including links to both the formal publication through the relevant DOI and the license). See: https://creativecommons.org/licenses/by-nc-nd/4.0/.

\section{References}

1. Nagahiro I, Andou A, Aoe M, et al. Pulmonary function, postoperative pain, and serum cytokine level after lobectomy: a comparison of VATS and conventional procedure. Ann Thorac Surg 2001;72:362-5.

2. Bendixen $M$, Jorgensen OD, Kronborg C, et al. Postoperative pain and quality of life after lobectomy via video-assisted thoracoscopic surgery or anterolateral thoracotomy for early stage lung cancer: a randomised controlled trial. Lancet Oncol 2016;17:836-44.

3. Erkılınç A, Gürcü ME. Pain Management for the Thoracic Surgical Patient. In: Nistor CE, Tsui S, Kırali K et al., editors. Thoracic Surgery: Cervical, Thoracic and Abdominal Approaches. Cham: Springer International Publishing; 2020:63-73.

4. Batchelor TJP, Rasburn NJ, Abdelnour-Berchtold E, et al. Guidelines for enhanced recovery after lung surgery: recommendations of the Enhanced Recovery After Surgery (ERAS $\left.{ }^{\circledR}\right)$ Society and the European Society of Thoracic Surgeons (ESTS). Eur J Cardiothorac Surg 2019;55:91-115.

5. Stokes SM, Wakeam E, Antonoff MB, et al. Optimizing health before elective thoracic surgery: systematic review of modifiable risk factors and opportunities for health services research. J Thorac Dis 2019;11:S537-54.

6. Kaplowitz J, Papadakos PJ. Acute Pain Management for Video-Assisted Thoracoscopic Surgery: An Update. J Cardiothorac Vasc Anesth 2012;26:312-21.

7. Wildgaard K, Ringsted TK, Hansen HJ, et al. Quantitative sensory testing of persistent pain after video-assisted thoracic surgery lobectomy. Br J Anaesth 2012;108:126-33.

8. Bertrand PC, Regnard JF, Spaggiari L, et al. Immediate and long-term results after surgical treatment of primary spontaneous pneumothorax by VATS. Ann Thorac Surg 1996;61:1641-5.

9. Brinck EC, Tiippana E, Heesen M, et al. Perioperative intravenous ketamine for acute postoperative pain in adults. Cochrane Database Syst Rev 2018;12:CD012033.

10. Laskowski K, Stirling A, McKay WP, et al. A systematic review of intravenous ketamine for postoperative analgesia. Can J Anaesth 2011;58:911-23.

11. Jouguelet-Lacoste J, La Colla L, Schilling D, et al. The 
use of intravenous infusion or single dose of low-dose ketamine for postoperative analgesia: a review of the current literature. Pain Med 2015;16:383-403.

12. Moyse DW, Kaye AD, Diaz JH, et al. Perioperative Ketamine Administration for Thoracotomy Pain. Pain Physician 2017;20:173-84.

13. Thiruvenkatarajan V, Wood R, Watts R, et al. The intraoperative use of non-opioid adjuvant analgesic agents: a survey of anaesthetists in Australia and New Zealand. BMC Anesthesiol 2019;19:188.

14. Fu ES, Miguel R, Scharf JE. Preemptive ketamine decreases postoperative narcotic requirements in patients undergoing abdominal surgery. Anesth Analg 1997;84:1086-90.

15. Guignard B, Coste C, Costes H, et al. Supplementing desflurane-remifentanil anesthesia with small-dose ketamine reduces perioperative opioid analgesic requirements. Anesth Analg 2002;95:103-8.

16. Kararmaz A, Kaya S, Karaman H, et al. Intraoperative intravenous ketamine in combination with epidural analgesia: postoperative analgesia after renal surgery. Anesth Analg 2003;97:1092-6.

17. Loftus RW, Yeager MP, Clark JA, et al. Intraoperative ketamine reduces perioperative opiate consumption in opiate-dependent patients with chronic back pain undergoing back surgery. Anesthesiology 2010;113:639-46.

18. Parikh B, Maliwad J, Shah VR. Preventive analgesia: Effect of small dose of ketamine on morphine requirement after renal surgery. J Anaesthesiol Clin Pharmacol 2011;27:485-8.

19. Argiriadou H, Papagiannopoulou P, Foroulis CN, et al. Intraoperative infusion of $\mathrm{S}(+)$-ketamine enhances postthoracotomy pain control compared with perioperative parecoxib when used in conjunction with thoracic paravertebral ropivacaine infusion. J Cardiothorac Vasc Anesth 2011;25:455-61.

20. Kaya FN, Turker G, Basagan-Mogol E, et al. Preoperative multiple-injection thoracic paravertebral blocks reduce postoperative pain and analgesic requirements after videoassisted thoracic surgery. J Cardiothorac Vasc Anesth 2006;20:639-43

21. Chumbley GM, Thompson L, Swatman JE, et al. Ketamine infusion for $96 \mathrm{hr}$ after thoracotomy: Effects on acute and persistent pain. Eur J Pain 2019;23:985-93.

22. Joseph C, Gaillat F, Duponq R, et al. Is there any benefit to adding intravenous ketamine to patientcontrolled epidural analgesia after thoracic surgery? A randomized double-blind study. Eur J Cardiothorac Surg 2012;42:e58-65.

23. Suzuki M, Haraguti S, Sugimoto K, et al. Low-dose Intravenous Ketamine Potentiates Epidural Analgesia after Thoracotomy. Anesthesiology 2006;105:111-9.

24. D'Alonzo RC, Bennett-Guerrero E, Podgoreanu M, et al. A randomized, double blind, placebo controlled clinical trial of the preoperative use of ketamine for reducing inflammation and pain after thoracic surgery. J Anesth 2011;25:672-8.

25. Yazigi A, Abou-Zeid H, Srouji T, et al. The effect of lowdose intravenous ketamine on continuous intercostal analgesia following thoracotomy. Ann Card Anaesth 2012;15:32-8.

26. Tena B, Gomar C, Rios J. Perioperative epidural or intravenous ketamine does not improve the effectiveness of thoracic epidural analgesia for acute and chronic pain after thoracotomy. Clin J Pain 2014;30:490-500.

27. Mendola C, Cammarota G, Netto R, et al. S(+)-ketamine for control of perioperative pain and prevention of post thoracotomy pain syndrome: a randomized, double-blind study. Minerva Anestesiol 2012;78:757-66.

28. Dualé C, Sibaud F, Guastella V, et al. Perioperative ketamine does not prevent chronic pain after thoracotomy. Eur J Pain 2009;13:497-505.

29. Chazan S, Buda I, Nesher N, et al. Low-dose ketamine via intravenous patient-controlled analgesia device after various transthoracic procedures improves analgesia and patient and family satisfaction. Pain Manag Nurs 2010;11:169-76.

30. Nesher N, Serovian I, Marouani N, et al. Ketamine spares morphine consumption after transthoracic lung and heart surgery without adverse hemodynamic effects. Pharmacol Res 2008;58:38-44.

31. Kafali H, Aldemir B, Kaygusuz K, et al. Small-dose ketamine decreases postoperative morphine requirements. Eur J Anaesthesiol 2004;21:916-7.

32. Aveline C, Hetet HL, Vautier P, et al. Peroperative ketamine and morphine for postoperative pain control after lumbar disk surgery. Eur J Pain 2006;10:653-8.

33. Pacreu S, Fernandez Candil J, Molto L, et al. The perioperative combination of methadone and ketamine reduces post-operative opioid usage compared with methadone alone. Acta Anaesthesiol Scand 2012;56:1250-6.

34. Aveline C, Gautier JF, Vautier P, et al. Postoperative analgesia and early rehabilitation after total knee replacement: a comparison of continuous low-dose intravenous ketamine versus nefopam. Eur J Pain 
2009;13:613-9.

35. Kwok RF, Lim J, Chan MT, et al. Preoperative ketamine improves postoperative analgesia after gynecologic laparoscopic surgery. Anesth Analg 2004;98:1044-9.

36. Gorlin AW, Rosenfeld DM, Ramakrishna H. Intravenous sub-anesthetic ketamine for perioperative analgesia. J Anaesthesiol Clin Pharmacol 2016;32:160-7.

37. Schwenk ES, Viscusi ER, Buvanendran A, et al. Consensus Guidelines on the Use of Intravenous Ketamine Infusions for Acute Pain Management From the American Society of Regional Anesthesia and Pain Medicine, the American Academy of Pain Medicine, and the American Society of Anesthesiologists. Reg Anesth Pain Med 2018;43:456-66.

38. Wang J, Echevarria GC, Doan L, et al. Effects of a single subanaesthetic dose of ketamine on pain and mood after laparoscopic bariatric surgery: A randomised doubleblind placebo controlled study. Eur J Anaesthesiol 2019;36:16-24.

39. Avidan MS, Maybrier HR, Abdallah AB, et al. Intraoperative ketamine for prevention of postoperative delirium or pain after major surgery in older adults: an international, multicentre, double-blind, randomised clinical trial. Lancet 2017;390:267-75.

40. Mion G. Ketamine stakes in 2018: Right doses, good choices. Eur J Anaesthesiol 2019;36:1-3.

41. Zanos P, Moaddel R, Morris PJ, et al. Ketamine and Ketamine Metabolite Pharmacology: Insights into Therapeutic Mechanisms. Pharmacol Rev 2018;70:621-60.

42. Zhang X, Shu L, Lin C, et al. Comparison Between Intraoperative Two-Space Injection Thoracic Paravertebral Block and Wound Infiltration as a Component of Multimodal Analgesia for Postoperative Pain Management After Video-Assisted Thoracoscopic Lobectomy: A Randomized Controlled Trial. J Cardiothorac Vasc Anesth 2015;29:1550-6.

43. Kaya FN, Turker G, Mogol EB, et al. Thoracic paravertebral block for video-assisted thoracoscopic surgery: single injection versus multiple injections. J Cardiothorac Vasc Anesth 2012;26:90-4.

44. Borys M, Hanych A, Czuczwar M. Paravertebral Block Versus Preemptive Ketamine Effect on Pain Intensity after Posterolateral Thoracotomies: A Randomized Controlled Trial. J Clin Med 2020;9:793.

45. Tan TL, Longenecker AS, Rhee JH, et al. Intraoperative Ketamine in Total Knee Arthroplasty Does Not Decrease Pain and Narcotic Consumption: A
Prospective Randomized Controlled Trial. J Arthroplasty 2019;34:1640-5.

46. Van Elstraete AC, Lebrun T, Sandefo I, et al. Ketamine does not decrease postoperative pain after remifentanilbased anaesthesia for tonsillectomy in adults. Acta Anaesthesiol Scand 2004;48:756-60.

47. Tang C, Xia Z. Dexmedetomidine in perioperative acute pain management: a non-opioid adjuvant analgesic. J Pain Res 2017;10:1899-904.

48. Cai X, Zhang P, Lu S, et al. Effects of Intraoperative Dexmedetomidine on Postoperative Pain in Highly Nicotine-Dependent Patients After Thoracic Surgery: A Prospective, Randomized, Controlled Trial. Medicine 2016;95:e3814.

49. Habibi V, Kiabi FH, Sharifi H. The Effect of Dexmedetomidine on the Acute Pain After Cardiothoracic Surgeries: A Systematic Review. Braz J Cardiovasc Surg 2018;33:404-17.

50. Choi JJ, Kim K, Park HY, et al. CONSORT the effect of a bolus dose of dexmedetomidine on postoperative pain, agitation, and quality of recovery after laparoscopic cholecystectomy. Medicine 2021;100:e24353.

51. Tsubokawa N, Harada H, Takenaka C, et al. Comparison of Postoperative Pain after Different Thoracic Surgery Approaches as Measured by Electrical Stimulation. Thorac Cardiovasc Surg 2015;63:519-25.

52. Mitchell JD. Techniques of VATS lobectomy. J Thorac Dis 2013;5 Suppl 3:S177-81.

53. Bayman EO, Parekh KR, Keech J, et al. Preoperative Patient Expectations of Postoperative Pain Are Associated with Moderate to Severe Acute Pain After VATS. Pain Med 2019;20:543-54.

54. Tiefenthaler W, Pehboeck D, Hammerle E, et al. Lung function after total intravenous anaesthesia or balanced anaesthesia with sevoflurane. Br J Anaesth 2011;106:272-6.

55. Sohn H-M, Jheon SH, Nam S, et al. Magnesium sulphate improves pulmonary function after videoassisted thoracoscopic surgery: A randomised doubleblind placebo-controlled study. Eur J Anaesthesiol 2017;34:508-14.

56. Mildh L, Taittonen M, Leino K, et al. The effect of lowdose ketamine on fentanyl-induced respiratory depression. Anaesthesia 1998;53:965-70.

57. Eikermann M, Grosse-Sundrup M, Zaremba S, et al. Ketamine activates breathing and abolishes the coupling between loss of consciousness and upper airway dilator muscle dysfunction. Anesthesiology 2012;116:35-46.

58. Jonkman K, van Rijnsoever E, Olofsen E, et al. Esketamine 
counters opioid-induced respiratory depression. Br J Anaesth 2018;120:1117-27.

59. Li L, Vlisides PE. Ketamine: 50 Years of Modulating the Mind. Front Hum Neurosci 2016;10:612.

60. Wang WF, Liu S, Xu B. A study of the protective effect and mechanism of ketamine on acute lung injury induced by mechanical ventilation. Eur Rev Med Pharmacol Sci

Cite this article as: Suksompong S, Chaikittisilpa N, Wanchiange S, Poolsuppasit S, Thongcharoen P, Limratana P. Low dose intraoperative ketamine infusion with multilevel paravertebral block for pain after video-assisted thoracic surgery: a randomized-controlled study. Ann Palliat Med 2021;10(7):7258-7269. doi: 10.21037/apm-21-766
2017;21:1362-7.

61. Michelet P, Guervilly C, Helaine A, et al. Adding ketamine to morphine for patient-controlled analgesia after thoracic surgery: influence on morphine consumption, respiratory function, and nocturnal desaturation. Br J Anaesth 2007;99:396-403. 